Regards sur l'économie allemande

Bulletin économique du CIRAC

72 | 2005

Varia

\title{
Système de formation : le palmarès des Länder
}

\section{Isabelle Bourgeois}

\section{OpenEdition}

Journals

Édition électronique

URL : http://journals.openedition.org/rea/298

DOI : $10.4000 /$ rea. 298

ISBN : 978-2-8218-0840-9

ISSN : 1965-0787

Éditeur

CIRAC

Édition imprimée

Date de publication : 1 juillet 2005

Pagination : 37-38

ISSN : 1156-8992

Référence électronique

Isabelle Bourgeois, "Système de formation : le palmarès des Länder », Regards sur l'économie allemande [En ligne], 72 | juillet 2005, document 2, mis en ligne le 23 juin 2008, consulté le 15 septembre 2020. URL : http://journals.openedition.org/rea/298

Ce document a été généré automatiquement le 15 septembre 2020.

(C) CIRAC 


\title{
Système de formation : le palmarès des Länder
}

\author{
Isabelle Bourgeois
}

\section{Championne : la Bavière}

1 Depuis le choc qu'a été outre-Rhin la publication du rapport PISA de l'OCDE, l'Allemagne s'interroge sur les performances de son système de formation: du Kindergarten à l'université en passant par la formation professionnelle (voir REA 66/04 et 69/04). On lui reproche de ne pas jouer son rôle d'ascenseur social, de ne dispenser qu'insuffisamment les compétences de base (le taux d'illettrisme est de l'ordre de $10 \%$ ), de négliger la constitution d'une élite universitaire. Les reproches sont avivés par le coût des formations : $175000 €$ par enfant, du début de la scolarité à la fin des études universitaires. Pour accroître les performances du système, indispensables à l'économie du savoir, il doit être réformé en profondeur. Les différents axes proposés incluent tous une approche en terme de compétition fondée sur la concurrence des sites d'éducation et de recherche. L'institut IW proche de la fédération de l'industrie BDI vient ainsi de publier une étude sur le coût comparé du système de formation dans les Länder. Elle résume les principales conclusions du programme Bildungsmonitor Deutschland, luimême un prolongement d'une comparaison internationale de l'économie de la formation engagée en 2003. Il ressort de ce benchmarking des Länder allemands que, globalement, la Bavière et le Bade-Wurtemberg sont en pointe en termes d'efficience, alors que trois petits Länder sont à la traîne : Berlin, Brême et la Sarre.

Systèmes de formation : palmarès des Länder

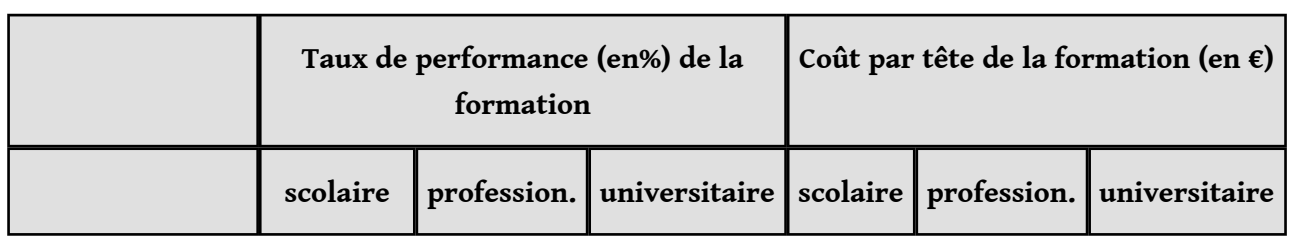




\begin{tabular}{|c|c|c|c|c|c|c|}
\hline $\begin{array}{l}\text { Bade- } \\
\text { Wurtemberg }\end{array}$ & 59,2 & 68,2 & 54,9 & 4900 & 4000 & 8570 \\
\hline Basse-Saxe & 46,0 & 48,2 & 47,8 & 4800 & 3400 & 9110 \\
\hline Bavière & 66,5 & 64,7 & 51,8 & 5100 & 3200 & 8340 \\
\hline Berlin & 39,4 & 31,1 & 49,2 & 5700 & 3300 & 7530 \\
\hline Brandebourg & 52,3 & 46,4 & 41,7 & 4400 & 2300 & 6020 \\
\hline Brême & 28,1 & 41,3 & 54,7 & 5200 & 3300 & 5940 \\
\hline Hambourg & 46,5 & 58,7 & 46,5 & 6600 & 4400 & 6430 \\
\hline Hesse & 40,6 & 51,7 & 40,6 & 4700 & 3400 & 5870 \\
\hline Mecklembourg & 49,9 & 41,4 & 54,1 & 4400 & 2400 & 8580 \\
\hline $\begin{array}{l}\text { Rhénanie du N.- } \\
\text { Westphalie }\end{array}$ & 49,0 & 42,6 & 39,5 & 4800 & 3200 & 6950 \\
\hline $\begin{array}{l}\text { Rhénanie- } \\
\text { Palatinat }\end{array}$ & 47,3 & 47,3 & 42,8 & 4600 & 3200 & 6180 \\
\hline Sarre & 41,4 & 47,2 & 48,3 & 4300 & 3300 & 8610 \\
\hline Saxe & 61,0 & 52,6 & 52,6 & 4800 & 2700 & 7850 \\
\hline Saxe-Anhalt & 37,0 & 44,5 & 42,9 & 5100 & 2800 & 8870 \\
\hline $\begin{array}{l}\text { Schleswig- } \\
\text { Holstein }\end{array}$ & 55,8 & 51,2 & 47,6 & 4700 & 3400 & 7390 \\
\hline Thuringe & 51,9 & 47,6 & 47,7 & 5700 & 3200 & 8340 \\
\hline Moyenne & 50,8 & 53,5 & 45,8 & 4900 & 3300 & 7510 \\
\hline
\end{tabular}

Sources : Taux de performance : A. PLÜNNECKE, O. STETTES, Bildung in Deutschland. Ein Benchmarking der Bundesländer aus bildungsökonomischer Perspektive, IW-Analysen, $n^{\circ}$ 10/2005. Coût de la formation : Destatis/IWD, $n^{\circ}$ 20/05.

\section{INDEX}

Mots-clés : formation, Länder 